\title{
Primary Physical Science for Student Teachers at Kindergarten and Primary School Levels: Part I-Foundations of an Imaginative Approach to Physical Science
}

\author{
Federico Corni $^{1}$ (D) $\cdot$ Hans U. Fuchs ${ }^{2}$ (D)
}

Received: 20 July 2019 / Accepted: 6 December 2019 / Published online: 3 January 2020

(c) The Author(s) 2020

\begin{abstract}
This is a theoretical paper in which we describe the motivation for and the design of a novel primary physics course for student teachers at kindergarten and primary school levels that uses cognitive tools such as metaphor, analogy, and narrative. The course has been taught in the master's program in teacher education at three Universities over the last 5 years. It is based upon a model of the experience of forces of nature that draws upon four existing frameworks in physics, narratology, cognitive linguistics, and a theory of the development of cognitive tools. In short, the course is created upon the foundations of an imaginative, metaphoric and narrative, approach to physical science in general and to forces of nature in particular. Student teachers who learn science based upon this model can more directly relate to how children themselves experience nature and become confident narrators of stories of forces of nature. We describe the notion of Force of Nature ("The Gestalt of Force of Nature") and explain what we mean by cognitive tools ("Cognitive Tools: Tools of Imagination") before showing in what sense modern macroscopic physics is both metaphoric and narrative at its core ("An Imaginative Approach to Physical Science"). In "A Systemic Imaginative Approach to Primary Physics", we give an outline of what is needed in order to apply the approach to a course for primary physics for student teachers. In the final section, we will discuss some questions and challenges raised by this approach and show that it is a viable avenue to bringing together science and the humanities, both for research and for teaching.
\end{abstract}

Federico Corni

federico.corni@unibz.it

Hans U. Fuchs

hans.fuchs@zhaw.ch

1 Faculty of Education, Free University of Bozen-Bolzano, 39042 Bressanone, Italy

2 Institute of Applied Mathematics and Physics, Zurich University of Applied Sciences at Winterthur, 8401 Winterthur, Switzerland 
Keywords Primary physics education $\cdot$ Pre-service teachers $\cdot$ Embodiment .

Metaphor · Narrative $\cdot$ Cognitive science

\section{Introduction}

Teaching physical science to student teachers at kindergarten and primary school levels poses a particular challenge we have wrestled with for a long time. How might the teachers of our children be educated to make sense of a science often deemed forbidding and apply what they have learned in the classroom? As we know from science education research of the past decades, learning a formal science such as physics and then passing it on to children, poses major problems the roots of which are not yet fully understood.

We have therefore decided to take a fresh look at what we know about how humans encounter and make sense of physical nature. Central to an answer that is emerging is the notion of a perceptual unit (gestalt) we call Force of Nature. We claim that perception and conceptual elaboration of different forces of nature such as water, wind, fire, ice, light, soil, food, electricity and motion, and their interactions, guide much of human engagement with and understanding of nature and, consequently, of physical science (see "The Gestalt of Force of Nature" for a detailed description of Forces of Nature).

The result of our efforts is a proposal for a new model for physical science education that draws on a small number of existing frameworks in physics, narratology, cognitive linguistics, and a theory of the development of cognitive tools (Fig. 1). Put very briefly and generally, the model creates a framework for an imaginative (fundamentally metaphoric and narrative) approach to the teaching of physical science.

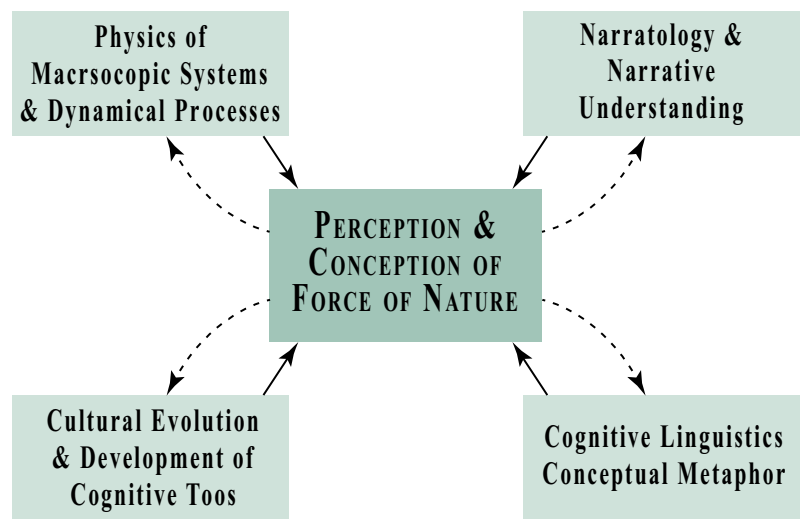

Fig. 1 Sources of a model of the nature and role of a perceptual unit (gestalt) we call Force of Nature. The model feeds back onto-provides some additional perspectives for-the already existing fields it draws upon. Elements in this figure are explained in the text 


\section{Original Motivation}

Our original motivation for taking this fresh look was at least twofold, rooting in the development of modern macroscopic physics on the one hand and the teaching of physics (to student teachers in Italy and engineering students in Switzerland) on the other. Developments in modern continuum physics have taught us how progress in this field depended upon the use of analogical reasoning in particular, and imagistic thinking in general, for uniting separate theories of different phenomena (fluids, electricity, heat, substances, motion) and developing a theory of the dynamics of heat (Fuchs 2010[1996]). This experience provided the background for searching for a model of figurative conceptual structure of macroscopic physical science (Fuchs 2006, 2010).

The second motivating push came from the realization that a traditional physics course, and even courses based upon recent advances in the application of cognitive science to physics education, would not do justice to the needs and motivations of student teachers at kindergarten and primary school levels. It became quite clear, in our minds, that a fresh start was required for student teachers. Students should be exposed to encounters with physical nature and physics in a form that would parallel that of the children they would be charged to educate. This led us to develop a fundamentally imaginative approach to primary physical science education (Corni 2013; Corni et al. $2019 \mathrm{a}, \mathrm{b})$ that makes use of recent investigations into the imaginative structure of macroscopic physical science (Fuchs 2006, 2014) and cognitive tools (Egan 1997) such as metaphor, analogy, and narrative (Lakoff and Johnson 1980; Gentner 1983; Fauconnier 1997; Bruner 1990; Turner 1996; Herman 2009).

\section{Primary Physics: Integrating Physics with Cognitive Tools}

An important element of our thinking that has led to the design of our physics course has to do with how we define primary physics or primary physical science. The term primary is used in a dual sense. It means early in the sense of education for children when they build their primary understanding of the world and it refers to the understanding of concepts of science that may rightly be called primary, i.e., the concepts and ideas that form the roots of scientific thought and theories. These elements of understanding are important not only for children but for everyone, at any age, for a meaningful approach to physical reality.

This way of thinking about primary physics underlies how we see the relationship between its conceptual structure and how we can learn and understand it. The structure of the object of study (physics) should be continuous with the way we interact with it. We feel we have made progress in identifying a possible solution to this challenge: our mind works imaginatively ("Cognitive Tools: Tools of Imagination"), and theories of physical processes make use of imaginative structures ("An Imaginative Approach to Physical Science"). It is our goal to identify imaginative forms in physical science and make them available to our students so their minds can correspondingly engage with the object of their study - this should hold for student teachers in our physics course as well as for their future students in primary school and in kindergarten. In other words, 
we want to formulate a course that creates a tight unity between physical science and the cognitive tools at our disposal.

\section{The Physics Course ${ }^{1}$}

Over the last few years, the considerations described in the previous paragraphs have led to a new physics course for student teachers taught primarily during their third year of studies. Briefly stated, the course is created upon the foundations of an imaginative approach to physical science in general and to forces of nature in particular. Students are expected to develop an understanding of physical phenomena encountered in nature and in our technical and social environments; the form and quality of this understanding are supposed to be meaningful particularly in a teacher's interaction with children. The course educates student teachers in the use of metaphor, analogy, and narrative forms in their encounters with physics. Above all, it encourages student teachers to imagine their role as confident authors and narrators of stories of forces of nature once they begin their professional careers.

In the lectures, we introduce students to the concepts of imaginative structuresmetaphor theory and narratology, in particular-and to macroscopic physical science. In the laboratory, we let students work on experiments, creation and use of (computer) models of dynamical processes, design and production of stories of forces of nature, and the performance of "energy plays" that show the role of energy in the interaction of forces of nature. Students who get an assignment relating to physical science during their apprenticeship phase, are tutored by the lecturer of the course. For such apprenticeships, they design and use stories of forces of nature and produce learning materials and activities motivated by these stories. In some cases, the apprenticeships can be the basis of research-action work that results in a master thesis.

\section{Structure of the paper}

This paper is structured as follows. In "The Gestalt of Force of Nature", the notion of Force of Nature is elaborated upon. We then present a more detailed outline of results of cognitive science and the idea of cognitive tools of imagination ("Cognitive Tools: Tools of Imagination"). The issue of imaginative forms in theories of physical science is dealt with in "An Imaginative Approach to Physical Science" and "A Systemic Imaginative Approach to Primary Physics" where we again stress how important we believe the integration of an imaginative approach to physics with appropriate cognitive tools such as metaphor and narrative to be. We conclude the paper with a discussion of some observations and open questions.

\footnotetext{
1 The course has been taught at the University of Modena and Reggio Emilia since 2013 and at the Free University of Bozen-Bolzano since 2014, in the same master's program in teacher education. Lectures and laboratories have also been done in the academic year 2014-2015 at the University of Verona.
} 


\section{The Gestalt of Force of Nature}

Given how important the notion of Force of Nature is to our model of interacting with and understanding of nature and science, we shall now discuss what we mean by this term. ${ }^{2}$ As we do this, we will have to draw on elements of physics and cognitive science that will be presented in more detail only later.

By Forces of Nature we mean a medium-scale ${ }^{3}$ perceptual unit or perceptual gestalt that is most easily associated with and recognized as any form of powerful agency (Fuchs 2006, 2015). Examples of Forces of Nature are water, wind, fire, ice, electricity, light, food, soil, gravity, and motion, just to mention some of the more obvious cases. We notice that we can categorize some of the examples more abstractly by speaking of heat and cold instead of fire and ice, or chemical substances instead of food or soil. Quite formally, in macroscopic physics, the list is made up of fluids, electricity and magnetism, heat, substance(s), gravity, and linear and rotational motion.

Importantly, Forces of Nature is a class within the larger category of the Gestalt of Force. In everyday life, we recognize social and cultural forces and forces of our psyche as well.

\section{Examples of Force}

Take as an example the social role of a particular group of people. As we perceive their role, we can identify three main aspects that help us reason about the phenomenon. There is first the aspect of status of that group-we conceptualize this in terms of high-low, i.e., the UP-DOwn (verticality or level) image schema (see "Cognitive Tools: Tools of Imagination"). This schema is projected metaphorically upon the aspect of status which helps us structure status as a concept. In particular, it helps us identify differences of status of this group relative to others (see, for instance, how an ethnologist makes use of this aspect of perception in conceptualizing grading, gradients, and degradation in social relations and in our relation to nature; Kockelman 2016).

Second, the group can be large or small, an aspect we structure in terms of size or amount as in amount of SUBSTANCE. Note that other image schematic structures are associated with the substance aspect such as existing inside or outside of a certain physical or metaphoric CONTAINER or being able to move along a physical or metaphoric trajectory or PATH. (Again, for more background on image schemas and metaphoric projections, see "Cognitive Tools: Tools of Imagination".)

Third, in its dealings with the rest of society, this group has more or less powerit is (or is not) a powerful player, actor, or agent. This finally makes the phenomenon of the existence and actions of this group a force.

\footnotetext{
${ }^{2}$ It is important to state at the outset that we do not use the term force in the sense of mechanics proper but in its primitive sense of phenomena that are endowed with power.

3 The term scale as it is used here refers to temporal, spatial, and systemic extent or "size."
} 
Let us now talk about a case of a Forces of Nature. We intentionally use an example that does not appear explicitly in this form in formal physical or chemical science: laundry soap. Perception presents us with cases of soap that are more or less aggressive, or strong, chemically speaking. Aggressive or mild creates a polarity that is graded along a scale (see the SCALE image schema, "Cognitive Tools: Tools of Imagination")—-we are dealing here with the aspect of intensity of the phenomenon.

Naturally, we can use more or less soap, meaning, we see the aspect of an amount (of substance) associated with laundry soap as a force. What makes soap a force, finally, is our knowledge that it will be more or less powerful as we do our laundry. Moreover, it appears that the amount of clothing that can be washed clean (starting from a certain level of being dirty) depends upon a combination of how chemically aggressive the soap is and how much we use of it.

\section{Force in the Larger Cognitive Context}

Intensity, quantity, and power are not everything when we conceptualize natural, social, cultural, and psychological phenomena. Typically, a complex metaphoric web is created that makes use of additional schematic resources (see "Cognitive Tools: Tools of Imagination" for image schemas and metaphors, and "An Imaginative Approach to Physical Science" for an application of the cognitive linguistic framework to physical science).

To give just one small example, amounts of substances are not just large or small, they move into and out of containers, are moved along certain paths because of differences of intensity, obstructed or enabled in their actions, etc. So, we might say that electricity is stored in two "communicating" capacitors and flows, driven by the difference of electric potential (tension) between the capacitors through a wire (conductor or resistor) that enables/obstructs the flow of electricity (i.e., the current of charge). CONTAiner, IN-OUT, PATH, SUBSTANCE, DIFFERENCE, TENSION, OBSTRUCTING or ENABLING, are all schemas that are used in reasoning (see "Cognitive Tools: Tools of Imagination"). In this manner, rich mental worlds are created that allow us to understand and respond to phenomena.

\section{Cognitive Tools: Tools of Imagination}

In recent years, a number of points important to us have emerged from investigations into cognition that are based upon the thesis of an embodied mind. In particular, we have made use of cognitive linguistics and narratology in order to study everyday language use concerning natural phenomena and science as well as conceptual structures in macroscopic physical science ("An Imaginative Approach to Physical Science").

In addition, and very importantly for the development of our thought, we have drawn on the work of Kieran Egan $(1997,2002)$ that might be summarized under the heading of evolution and development of cognitive tools. According to Egan, cognitive tools are tools that have been made available by cultures and are in some 
form "recapitulated" by the individual growing up in such cultures. These tools are, in important ways, related to imagination and evolving forms of language use. To give an example, metaphor and narrative are cognitive tools that develop in, or are appropriated by, the mind of very young children going through a phase Egan calls mythic understanding (Egan 1988; for an application of this perspective to physical science education, see Fuchs 2012).

We shall now outline elements from these various frameworks we see as having particular relevance for our model of perception and conceptual elaboration of forces of nature.

\section{A General Take on Cognitive Tools}

Cognitive tools are the forms we think with-bonnes a penser, good things to think with. This is what Claude Levi-Strauss (1962) called some schematic forms of thought used by mythic peoples. We take the term cognitive tool from Kieran Egan's work $(1997,2002)$ and apply it to our field of inquiry. Egan describes growth and development of various cognitive tools in human history and individual development. According to Egan, cognitive tools such as binary opposites (polarity), metaphor, stories, humor, a sense of external reality, a sense of theoretical conceptual structures, etc., develop in an individual in the course of growing up through phases he calls mythic, romantic, and philosophical (Egan 1988, 1990, 1997). Importantly, these tools are tied to the development and mastery of forms of language use-oral for mythic culture, early literacy for romantic understanding, and mature literacy and the use of formal languages for philosophical tools. Since we are discussing primary science here, most of what we have to say refers to the first of these phasesmythic understanding.

Tools such as polarity (binary opposites), metaphor, analogical thinking, and stories appear with spoken language. They are readily available to relatively small children. Arguably, the power of metaphor and the love and understanding of stories such as fairy tales is at a prime during this phase that typically lasts from age 3 to 9 or 10 .

\section{Image Schemas}

Image schemas are not proper cognitive tools but foundational elements for forms of embodied imaginative thought such as metaphor; Johnson (1987) and Lakoff (1987) identified them in their studies of cognitive linguistics. Image schemas are basic perceptual units that develop through our interaction with the environment; among perceptual units forming in our mind, they are of particularly simple (primary) and abstract form (see also Hampe 2005). "A schema is a recurrent pattern, shape, and regularity in, or of, these ongoing ordering activities" (Johnson 1987, p. 29). Image schemas are basically unconscious conceptual structures that appear most directly as elements of source domains in metaphoric projections (see further below). 
Examples of image schemas are PATH, CONTAINER, IN-OUT, UP-DOWN (verticality), SUBSTANCE, AGENCY or CAUSATION, SCALE, CYCLE, PROCESS, and many more. We call such schemas small-scale perceptual gestalts (Fuchs 2015)—upon analysis, they exhibit limited structure (aspects) with internal logic that is used in reasoning. To give a couple of examples, the CONTAINER and IN-OUT schemas let us reason that a stone in one's hand that is in the jacket pocket is also inside the pocket, and the CYCLE and PATH schemas make us think about the blood circulatory system.

We shall now concentrate on the cognitive tools that are of most immediate interest to us-binary opposites (polarity), metaphor, and narrative; add to this list the perceptual gestalt of force we already discussed in "The Gestalt of Force of Nature".

\section{Polarity}

Understanding of polarities such as GOOD $\leftrightarrow$ EVIL, LIGHT $\leftrightarrow$ DARK, STRONG $\leftrightarrow$ WEAK, HOT $\leftrightarrow$ COLD, JUST $\leftrightarrow$ UNJUST, COURAGE $\leftrightarrow$ COWARDICE, LOVE $\leftrightarrow$ HATE, and so on, comes to us rather naturally and early, and so does mediating between the poles of a polarity. We may conjecture that they are the results of some of the most basic forms of perception-organisms are equipped to detect differences in intensities of qualities such as brightness, temperature, height, or psychological agitation. Learning about and expressing the experience of different thermal intensities that lie between the extremes of the Hот $\leftrightarrow$ COLD polarity, for instance, is an early achievement of embodied imagination. This example shows that we structure a polarity in terms of the SCALE image schema-a polarity spans a spectrum.

Binary opposites lead to an important concept. We easily form a feeling for the differences between two values of a scale such as two points along the HOT $\leftrightarrow$ COLD polarity; such differences are perceived as tensions that drive processes in nature, in society, and in our psyche.

Interestingly, when the totality of the various perceptions associated with a polarity (such as very hot-hot-warm-cold-very cold) is named with a noun (here, temperature), the concept is structured with the help of the schema of VERTICALITY (level or vertical scale). Temperature, speed, pressure, brightness-intensities, in general-are said to be either high or low or at a high or low level (rather than being big or small, or many or few). Here we see another cognitive tool of imagination appearing - that of metaphoric projection. Linguistic forms that let us speak of temperature as being high or low derive from the projection of the image schema of VERTICALITY onto the experience of hotness (see below).

Binary opposites are a prime structuring element of myths and stories (LevyStrauss 1962, 1978); they set up a tension that will be heightened and finally resolved in typical tales of events that engage our fantasy and imagination (Egan 1986, 1988, 2013; Fuchs 2013).

\section{Metaphor}

Conceptual metaphors are said to be figurative structures that are created by projection of embodied understanding of a domain (the source domain) onto another 
domain of experience (the target domain); see Lakoff and Johnson $(1980,1999)$. Metaphors are (possibly unconscious) structures of thought that let us produce concrete linguistic metaphoric expressions. So, the expression that heat flows through the wall of a building is a concrete linguistic example of the conceptual metaphor HEAT IS A FLUID SUBSTANCE.

Our understanding of experience such as stumbling over a stone, being exposed to a blast of heat when opening the door of a furnace, getting embarrassed when caught at a lie, surviving a tornado, etc., is structured in terms of smaller and larger webs of conceptual metaphors. The metaphor LIFE IS A JOURNEY shows that one way of understanding the very rich experience of life is in terms of our rich experience, knowledge, and understanding of journeys. Other metaphors for life are LIFE IS A STORY Or LIFE IS A STRUGGLE. You have traveled a long way since we first met would be an example of a concrete linguistic expression resulting from LIFE IS A JOURNEY.

To give another example, the gestalt of heat as a Forces of Nature is structured by a fairly large number of metaphoric projections; examples of these are the projections of schemas of VERTICALITY, FLUID QUANTITY, and AGENCY or CAUSATION. Here are a number of concrete expressions (taken from Internet searches) that exemplify what we mean; note that there is not a single use of literal language to be found:

- How do you collect heat in a passive solar house?

- This means heat flows "downhill" from hot to cold.

- ... heat is an agent of vast importance in chemical reactions...

- Law of the dependence of the active force of heat upon the tempera... (Clausius)

- This exterior heat lets the crust become crispy

- Heat makes me dizzy...

- Clouds and storms follow the warm water, pumping heat and moisture high into the atmosphere...

- Heat must balance cold...

A close analysis of everyday, scientific, and engineering language concerning thermal or other processes shows the large number of schemas that are used and projected in order for us to be able to talk sensibly about natural phenomena.

An important type of conceptual metaphor results when image schemas (which are small-scale embodied structures) are projected directly onto some experiential domain-such metaphors are called primary (Grady 1997, 2005a, b). Examples of primary metaphors are HAPPY IS UP, CATEGORIES ARE CONTAINERS, SIMILARITY IS CLOSENESS, PURPOSES ARE DESTINATIONS, (quantity of) ELECTRICITY IS A FLUID, etc. Up, container, closeness, or fluid, are among the simplest schemas that form in the human mind through recurring interaction of an organism with its surroundings.

\section{Narrative}

Single metaphors and the linguistic expressions associated with them form relatively small-scale imaginative structures. Webs of interconnected metaphors used for understanding larger-scale phenomena such as melting iron for casting machine 
parts or riding a bicycle up a hill, form medium-scale imaginative structures. But there are still larger-scale forms that populate our mind-namely, narratives or stories (Fuchs 2015; Fuchs et al. 2018). They help us deal with the perception of largescale events such as a forest fire, a winter storm, growing and harvesting crops, designing and constructing a bridge, or the birth of a child.

Characterizing stories as large-scale structures relies, partly, on their phenomenology - they usually tell the tales of several agents (forces) interacting in a more or less complex world, recounting and explaining events that run over extended periods of time. Stories create experiential units, they have their own experientiality (Caracciolo 2014): we know what it is when we encounter a story-it is different from other forms of discourse. In particular, stories provide us with an overall sense of TIME, PLACE, and AGENCY (Ricoeur 1984).

In the following, we will use a model of narrative as a radial category ${ }^{4}$ showing prototype effects (Herman 2009). It allows us to consider different forms of narrative as belonging to the same category-such as descriptive narratives, narrative descriptions, explanations, stories, novels, myths, fairytales as all belonging to this category. By saying that stories are prototypical narratives, it tells us more clearly what we mean by story.

According to Herman (2009), four elements constitute the central member of the category of narrative. We will recount his list in slightly different words. Stories are narratives that include all of the following elements: (1) events; (2) (conscious) experiencing of events by agents; (3) tension for creating events; (4) reason or occasion for telling by a narrator.

Our perception of forces connects what we have discussed before with narrative. The particular form of our perception of natural, social, and psychological phenomena leads to the notion of powerful agents as the "movers and shakers" in natural phenomena. We will explore this in more detail in "An Imaginative Approach to Physical Science".

\section{Stories and Story-Worlds}

The distinction between stories and story-worlds (or narrative worlds) will prove important in the following. Stories are concrete narratives whereas story-worlds are the mental models we construct when we are exposed to stories-stories transport us into story-worlds. Put differently, stories are narratives told against the background of story-worlds.

\footnotetext{
4 According to the modern theory of categorization (Rosch 1973; Lakoff 1987), a radial category is one that has central or prototypical members as well as members that do not share that status, i.e., are less prototypical and more peripheral. The categories exhibit prototype effects. As an example, consider the category of chair; we might include such exemplars as a dining room chair, an office chair on wheels, a dentist's chair, a beanbag chair, a farmer's milking stool, and more. Most likely, we spontaneously grade this list according to what we consider to be a "real chair" or a prototype. There clearly are items in this list that are either closer or farther from the "center" of this category.
} 
In Story Logic, Herman (2002) defines story-worlds as follows: “[...] storyworlds [are construed] as mental models [...] supporting narrative understanding." (p. 17). He writes that

[I]n trying to make sense of a narrative, interpreters attempt to reconstruct not just what happened-who did what to or with whom, for how long, how often and in what order-but also the surrounding context or environment embedding existents, their attributes, and the actions and events in which they are more or less centrally involved. [...] storyworld points to a way interpreters of narrative reconstruct a sequence of states, events, and actions not just additively or incrementally but integratively or "ecologically".... (pp. 13-14)

To put this more simply and directly for our purpose, a story recounts the what of events and the story-world we construct informs us about the why. Applying this distinction to science, we will be able to refer to stories as simulations, and storyworlds as the models simulated (Fuchs 2015; see "An Imaginative Approach to Physical Science").

\section{Analogical Structures in the Descriptions of Forces of Nature}

The images referred to in the previous paragraphs are so basic and fundamentally important that it should not come as a surprise that they are quite ubiquitous. We do not seem to have, and do not seem to need, numerous different images that are projected metaphorically upon different phenomena, certainly not when it comes to creating meaning of our experience of nature. We recycle the few basic ideas and relations suggested by narratives (the fluidlike quantities are powerful agents interacting and living through events that unfold over time...) and metaphors (there is a relation between stored amount and intensity of an agent; there is a relation between differences of intensities and flows of the agent...) when we tell stories and create models of various forces of nature and the systems they are active in.

We can see metaphors for different forces of nature and analogies between them emerging from a blending mechanism (also called conceptual integration; Fauconnier 1997; Fauconnier and Turner 2002). Our experience of fluids creates a first mental space (input space 1 on the right in Fig. 2) from which we abstract core schemas relating to the behavior of fluids or, more generally speaking, fluidlike quantities (amount of fluid, electric charge, entropy, momentum, amount of substance, etc.; see "An Imaginative Approach to Physical Science"); among these schemas are QUANTITY, LEVEL Or PRESSURE, TENSION, FLOW, and CONTAINMENT. In blending theory, it is assumed that this leads to the creation of a new mental space called a generic space (bottom oval in Fig. 2). To some degree, this particular mental space is also structured by experience of other phenomena, but the main source will be that of fluid behavior. Now, our understanding exemplified by the generic space is projected metaphorically upon the experience of other forces such as heat, creating a mental 
space for heat (input space 2, oval on the left in Fig. 2; other forces are structured by analogous mental spaces).

Having different forces structured similarly to each other and to the first space relating to fluids allows for analogical comparison (two-sided horizontal arrows connecting input spaces 1 and 2) and leads to a new space called a blend (top oval in Fig. 2). In this blend, it is perfectly alright to say things like HEAT IS (LIKE) WATER or MOMENTUM BEHAVES LIKE ELECTRIC CHARGE, Or AN ELECTRIC CURRENT IS LIKE A CURRENT OF WATER, A CAPACITOR IS LIKE A VESSEL, etc. Note, these mappings do not represent metaphors; they are analogies.

\section{An Imaginative Approach to Physical Science}

In "Cognitive Tools: Tools of Imagination", we have taken a look at a number of cognitive tools that can help us understand the world around us. While the description has been kept fairly general, the examples included there suggest that tools of imagination such as metaphor and narrative can be applied to learning and teaching physical science. We can do serious physics based upon an imaginative approach to Forces of Nature-physical science is figurative, and therefore metaphoric and narrative, at its very core. ${ }^{5}$

\section{Identifying the Imaginative Structure of Continuum Physics}

We shall now show that continuum physics is built up from the same figurative structures that are used to reason about our experience of FORCE in everyday life (see Fuchs 2010 [1996]: Introduction; Fuchs 2014; Corni et al. 2018).

\footnotetext{
5 Since it is not common to associate formal physical theories with imaginative structures or with their application to early science education as we propose here, this statement needs to be clarified somewhat. We claim that we have ample reason not to erect an artificial barrier between primary understanding and formal science (see also the first sub-heading in the Summary, "Imaginative Primary Physical Science: Questions and Challenges" of this paper). Expressed still differently, we do not take our approach to Primary Physical Science to be a purely didactic one-indeed, it grew out of developments in modern continuum physics (Truesdell and Toupin 1960; Truesdell and Noll 1965; in particular, continuum thermodynamics: Truesdell 1984; Müller 1985; Jou et al. 1996), the physics of dynamical systems and a theory of dynamical thermal processes (Fuchs 2010 [1996]), finite-time thermodynamics (Sieniutycz and De Vos 2000; and references therein), and applications of these developments in engineering education (Scheidegger et al. 2013; Dumont et al. 2014). The link with imaginative structures has been worked out by Hestenes (2006) and Fuchs $(2006,2013)$. There is an interesting and important point regarding the role and our understanding of entropy in a dynamical theory of heat-it has been pointed out before that a direct and imaginative approach to thermodynamics is afforded by linking the old caloric theory with the notion of entropy and thereby create an extended version of the caloric theory for modern continuum physics (Callendar 1911; Falk 1985; Mares et al. 2008; Fuchs 2010 [1996]). Entropy is treated as thermal charge in modeling of dynamical engineering systems (Thoma 1975; Thoma and Mocellin 2006)—demonstrating how the use of analogy based upon conceptual integration (our Fig. 2) makes the concept not only accessibly but eminently useful beyond what is standard practice in physics and traditional physics education.
} 


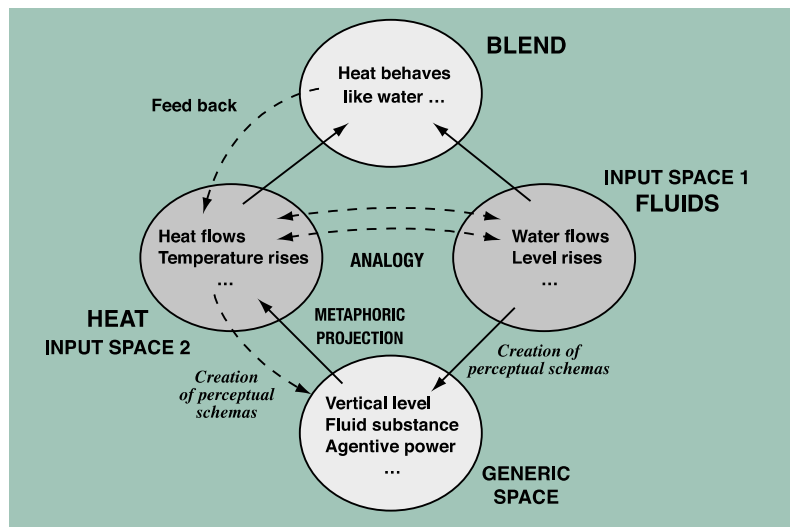

Fig. 2 Metaphors for fluids and heat and analogy between fluids and heat as a consequence of a blending mechanism

From a purely formal perspective, the structure of continuum physics appears as follows. A concrete theory contains fundamental or primitive quantities, laws of balance for fluidlike quantities, constitutive relations, and the energy principle. The fundamental or primitive quantities used in a theory of continuum physics are those that derive from an analysis of the gestalt of force applied to forces such as heat, electricity, substances, and motion. In the case of heat as a Forces of Nature, these are hotness (thermal intensity), entropy (caloric: quantity of heat), and conductive flux of entropy; for all other phenomena, there are analogous intensive and extensive quantities including the conductive fluxes. Understanding of these quantities derives from embodied experience by projection of image schemas upon the phenomena in question (Fuchs 2014).

Laws of balance of the fluidlike quantities ${ }^{6}$ (entropy, charge, amount of substance, momentum and angular momentum for the forces just listed) form the core of a theory; their mathematical structure makes use of metaphoric projections of schemas of (fluid) SUBSTANCE, AMOUNT, CONTAINER, SURFACE, IN-OUT, PATH (SOURCE-PATH-GOAL), COLLECTION, and FLOW, to name the most obvious. This is attested to by examples of natural and technical language use in describing what a law of balance stands for. For example, a body (CONTAINER) contains a certain amount of momentum (FLUID SUBSTANCE); it is separated from the surroundings by its surface (creating an IN-OUT situation). As a result of an interaction, momentum flows into or out of the body (through the surface) going from an initial to a final location along a particular path (SOURCE-PATH-GOAL). Inflow adds to, outflow subtracts from the store of momentum in the body (COLLECTION; see Lakoff and Nunez (2000) for a discussion of the metaphoric basis of mathematical procedures such as addition and subtraction).

\footnotetext{
6 The term "fluidlike" was introduced by Fuchs (2010 [1996]) to denote what has been called "substance-like" in an innovative physics course for high school (The Karlsruhe Physics Course; Herrmann 1989-1999, 2000; Schmid 1982, 1984; Falk et al. 1983). It denotes a subset of the extensive quantities of continuum physics for which laws of balance can be formulated.
} 
Constitutive relations make use of a large amount of schematic spatial and dynamic knowledge (Fuchs 2014). Just consider the examples of containment (of a fluidlike quantity) and its effect upon intensity, and the conductive transport of fluidlike quantities. Collecting and storing more entropy (caloric) in a simple material raises the thermal level (intensity: temperature). The conductive current density of entropy depends upon (1) the local temperature gradient that is understood in terms of the metaphor of a thermal landscape with its HIGHS and LOwS and STEEP or GENTLE slopes, and (2) how the nature of the path taken by entropy ENABLES or OPPOSES its flow (note the force dynamic schemas of LETTING, OPPOSITION, Or RESISTANCE; see Johnson 1987; Talmy 2000, for a detailed discussion of force dynamic schemas). Verticality, tension, and force dynamic schemas work together to create an imaginative world in which we understand the constitutive equations of continuum thermodynamics.

Finally, energy makes its entrance upon the scene as the power of a force-this is Sadi Carnot's image of the waterfall explaining the notion of la puissance du feu (the power of heat: Carnot 1824). Caloric flows from a higher to a lower levelthe strength of the flow and the height of its fall combine to determine the power of a fall of heat - this is the rate at which energy is made available in the fall of caloric, called availability in modern engineering thermodynamics (see Bejan et al. 1996; Fuchs 2010 [1996]). This is a concrete example for the embodied knowledge that quantity and quality of a phenomenon conjoined lead to its power. With this imaginative structure we create our understanding of a forces of nature. (In Table 1, we list some forces of nature with their levels/potentials, potential differences (tensions), and associated extensive (fluidlike) quantities- this gives an overview and demonstrates important analogies.)

\section{Stories of Forces of Nature: Narrative Framing of Natural Scenes}

Elements of theories of physics - concepts, relations, and the directly derivable consequences of basic assumptions, represented in the form of relations-are cast in metaphoric form. What happens then if we describe and model a concrete physical phenomenon? Do forms arise that are not in themselves single metaphors or webs of metaphors (and related figurative structures)? In other words, does something emerge that is not a simple sum of metaphoric expressions and relations? Can natural and technical scenes be framed narratively (see Fuchs 2015; Fuchs et al. 2018)?

We mentioned before that we believe categorizing macroscopic phenomena as Forces of Nature ("The Gestalt of Force of Nature") is central to characterizing the narrative nature of both the development of new theory and concrete applications of physical theory to events. Take as an example how architects and engineers work out the thermal dynamics of a building where heat is the prime agent that typically interacts with electricity, light, and fluids to create a moderately complex dynamical system. An architect might "walk" us through a model of a new building, telling the story of heat in order to convince us that the design of the structure was done properly. An image will develop in our minds and we might become able to reason about what could happen during a particularly severe winter storm. 
Table 1 Forces of nature and their potentials, potential differences, and extensive quantities

\begin{tabular}{|c|c|c|c|}
\hline Force of nature & Level/potential & Tension & Quantity \\
\hline Water & Pressure & $\begin{array}{l}\text { Pressure diff. (hydraulic } \\
\text { tension) }\end{array}$ & Amount of water \\
\hline Light & Brightness & Brightness diff. & Amount of light \\
\hline Heat & Temperature & $\begin{array}{l}\text { Thermal tension (temp. dif- } \\
\text { ference) }\end{array}$ & Caloric (amount of heat) \\
\hline Water in soil or air & Humidity & Humidity diff. & Amount of water \\
\hline Linear motion & Speed & Speed difference & $\begin{array}{l}\text { Momentum (quantity of } \\
\text { motion) }\end{array}$ \\
\hline Rotation & $\begin{array}{l}\text { rpm-s } \\
\text { (angular speed) }\end{array}$ & Diff. of angular speed & $\begin{array}{l}\text { Spin (quantity of rotational } \\
\text { motion) }\end{array}$ \\
\hline Food & Quality & Quality diff. & Quantity of food \\
\hline Rain & Intensity & Diff. of intensity & Amount of rain \\
\hline Wind & Speed & Speed difference & Amount of air \\
\hline Dissolved substance & Concentration & Diff. of concentration & Amount of substance \\
\hline Electricity & Electric potential & Electric tension (voltage) & $\begin{array}{l}\text { Quantity of electricity (electric } \\
\text { charge) }\end{array}$ \\
\hline
\end{tabular}

The same may be done for the benefit of a team of engineers charged with creating a dynamical computer model of the building. What is happening, especially in the latter case, is that the engineers "hear" allusions to the properties of heat (and the other agents) in relation to the physical structure of the building. They begin to imagine heat being produced and stored as well as flowing from room to room and through the walls of the building. They identify temperatures and see temperature differences as the causes of much of the dynamics they want to capture in their models; they show how the amount of heat defines the temperature of an element and how temperature differences cause heat to flow or pressures to change so that air and water circulate in the building; and they express how much sunlight is needed to produce a certain amount of heat.

If the engineers manage to create their computer model, they will use it to perform extensive simulations or "virtual experiments" in order to get a clearer understanding of possible forms of dynamics of the building in its environment. Each such simulation is similar to a story initially told by the architect, and the sum of all simulations forms a bundle of trajectories that lets the life of the building and the agents within emerge before our eyes. (See Wise 2011, for a detailed analysis of the meaning of narrative in computational physics.)

From the point of view of physics, something new has arisen: the particular model and the many concrete simulations are not simply contained in the theories that have been applied in model building. Indeed, model building is a creative act that reveals that all theories do is give us a toolkit from which to choose elements for the imaginative structures we are creating. Importantly, simulations introduce the temporal dimension of phenomena that is not directly part of the elements of theories-even if the parameter $t$ (time) appears in some of the equations typically listed 
in theories. Moreover, the dynamics of systems is not "in" theories; actually, it is not even in our models of a system-it arises in the act of simulation.

\section{Stories and Story-Worlds}

This brings us to the following analogy between narrative and applications of physics (Fuchs 2015). The relations applying between embodied concepts-the equations of balance, constitutive relations, and the energy principle-that make up our formal models of physical systems create story-worlds against whose background stories are told, i.e., the models are simulated. Models therefore correspond to storyworlds and simulation runs to particular narratives. In summary, the fact that our mind creates and makes use of the imaginative structure of Forces of Nature allows for stories of these forces to be told. Physics narratively frames natural and technical scenes by letting us create models of dynamical systems that are then simulated.

\section{A Systemic Imaginative Approach to Primary Physics}

We certainly do not want to insinuate that we teach continuum physics to our students. However, we take the form of conceptualization that is found in modern macroscopic physics and create what we call the physics of dynamical systems (Fuchs 2010 [1996], Chapters 1-9). From a formal mathematical viewpoint, this is simply a subset of continuum physics. However, it can be cast in a form that allows for different types of representation ranging from formal to purely qualitative, without loss of conceptual stringency and clarity. In short, what we teach is a form of physics of spatially uniform dynamical systems.

Rather than discussing the physics of dynamical systems in detail, we will present an example of observations of the behavior of a simple hydraulic system and its narrative and computational rendering. The description is augmented by a demonstration of analogical transfer of imaginative structures to thermal and electrical phenomena. The example provides a generalized and somewhat more formal description of what happens in the course. At the same time, it reflects typical topics we present to students.

\section{Working with Water}

Students are asked to fill a straight walled tank (Tank 2 in Fig. 3) through a pipe (Pipe 1 in Fig. 3) with the help of a pump that sets up a constant pressure difference. The tank has an outlet pipe (Pipe 2 in Fig. 3) in addition to the inlet pipe. Instead of a pump another tank can be used (Tank 1 in Fig. 3) where the water level is kept constant by continuously adding water by hand. This means that a student monitors the level of water in Tank 1 and keeps it constant by properly maintaining the inflow while other students record the level of water in Tank 2 (that may have been empty 
initially) and the outflow through Pipe 2 as functions of time (see the diagram on the right in Fig. 3).

A narrative description of what is done and observed might go as follows. Water in Tank 1 stands at a high level. As it flows into the almost empty Tank 2, the level there rises quickly at first. As the level rises and comes closer to the level in Tank 1 , the increase slows down. We observe that the outflow from Tank 1, as measured indirectly by how much water we have to supply, decreases as the level of water in Tank 2 goes up. Interestingly, the level in Tank 2 never reaches the height of water in Tank 1.

If the pipes are changed, made longer or shorter, thinner or thicker, the basic behavior is still the same. Tank 2 might fill more slowly or faster, and the steady level reached after some time will be closer to or farther from the level in Tank 1; this shows that the different pipes oppose (or enable) the flow of water differently (more or less strongly).

So far, this is a mostly descriptive form of a narrative-explanations are only hinted at. Still, this might be enough to activate the imagination of a modeler. If more is needed, the narrative can be repeated several times in slightly different forms where ideas for explanations become more apparent.

Here are some examples of such narrative extensions. Since water fills the first tank to a high level, this leads to a high hydraulic tension (pressure difference) for the water in the tank. Thanks to its intensity, the water is driven through the first pipe into Tank 2 letting the second level rise quickly-the water in Tank 1 is powerful. Initially, with very little water in Tank 2, the outflow through Pipe 2 is very weak because the driving force there is small-the intensity of the water in Tank 2 is low; but as the level of water in Tank 2 rises, this outflow becomes stronger. The water level serves as the driving force for water flowing out; if it is high, it can drive a strong current.

Despite the outflow, the water level in Tank 2 keeps rising. Indeed, it rises fast at first because the driving force for the flow through Pipe 1-the difference of levels in Tanks 1 and 2-is high leading to a strong current of water. If we keep the level of water in Tank 1 constant by continuously adding water, the rising level in Tank 2 leads to a lowering of the level difference in the two tanks leading to a smaller driving force resulting in a weaker current. So, the level in Tank 2 rises more and more slowly as time goes on. After some time, the level in Tank 2 also becomes constant; inflow and outflow balance and the amount of water stays constant.

The level in Tank 2 must remain below that in Tank 1 simply because water needs to keep flowing into the tank-remember, there is an outflow; this means that there must be a driving force, a difference of levels, between Tanks 1 and 2 . The intensity of water in Tank 2 must remain higher than that in Tank 1.

In its first form, the narrative is a little story that is then extended to include narrative explanations. From a technical viewpoint, it first resembles the description of a simulation of the system (either the real physical system in the laboratory or a computer model thereof) with explanations remaining subliminal. Later forms come close to what we could call a word-model: we are taking steps toward the construction of a storyworld, i.e., a mental model or model-world. 


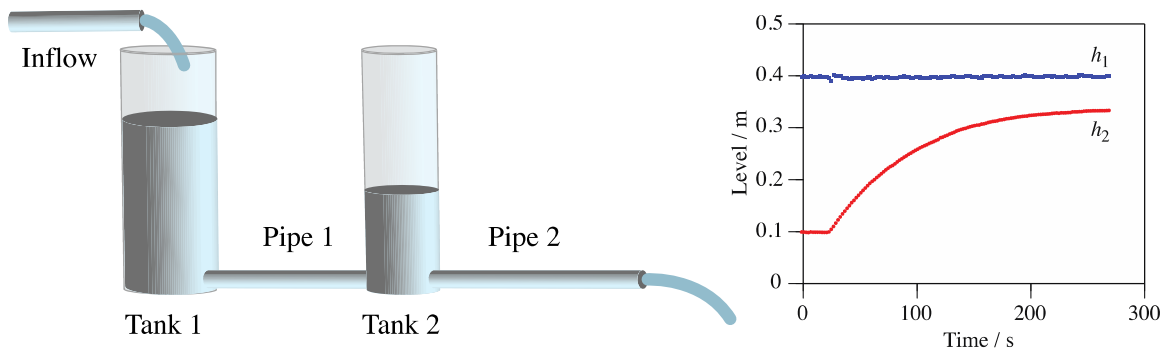

Fig. 3 Left: An experimental setup that allows filling of a tank (Tank 2) through a pipe at the bottom (Pipe 1) with the help of the equivalent of a pump that sets up a constant pressure difference (Tank 1). Tank 2 also has an outlet pipe (Pipe 2). Right: Experimental data of levels of water in the tanks as functions of time

\section{Metaphors, Narrative, and Formal Dynamical Models}

This little narrative - water as an agent that drives and is driven, levels as intensities of the agents and level differences as tensions that serve as driving forces, quantity of stored water determining tensions, and tensions along a pipe leading to flows that are opposed by the pipes-can be translated into a mathematical computer model. We use software ${ }^{7}$ that employs a graphical metaphoric language for translating our mental and linguistic metaphors into visual metaphors that are part of such a model (see Fuchs 2002). We need symbols for storage (stored quantities), transports of fluidlike quantities (flows), other variables such as levels (potentials), and numbers describing things like geometric sizes and other parameters (resistance, capacitance...). A model diagram for our example system is shown in Fig. 4.

If system dynamics software is used to translate the elements of a story-world into mathematical form, we are aided by visual symbols that represent metaphors. Combinations of reservoirs and flows express laws of balance for fluidlike quantities-here, the software creates the pertinent equations without us having to write them. Drawing a reservoir with an inflow and an outflow represents our image of how a fluid enters and leaves a reservoir, and whatever does not leave the reservoir after entering will be stored there.

\section{Adventures of Electricity and Heat: Using Analogy}

It is possible to build electric and thermal systems that behave quite similarly to what we have just seen in the case of a hydraulic system. In Fig. 5, we see data for the behavior of the temperature of a body being heated while cooling at the same time, and of a capacitor being charged while losing charge through a parallel resistor. Quite obviously, the forms of temporal behavior of relevant quantities are the same as that for the water levels reported in Fig. 3. Apart from proper names, the story told about water can also be told about heat and electricity.

\footnotetext{
7 Here are some examples: Stella (https://www.iseesystems.com), BerkeleyMadonna (https://www.Berke leyMadonna.com), or InsightMaker (https://www.insightmaker.com).
} 


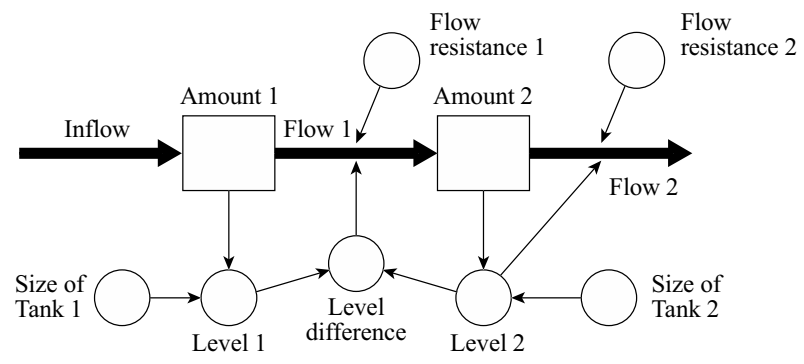

Fig. 4 A diagram of a dynamical model rendered in the form used in system dynamics tools. The diagram highlights the contrast between fluidlike quantities (rectangles for reservoirs and fat arrows for flows) and other variables and constants (circles). The thin arrows suggest relationships between variables

\section{Using Analogy}

In "Cognitive Tools: Tools of Imagination", we discussed the root of analogy in our treatment of Forces of Nature. We can now see what this means for the learning of macroscopic physical science. If we learn about ideas that are contained in a certain phenomenon (electricity), much of what we learn there can be transferred to the study of another field (thermal processes). This relationship can be reversed as well-if we feel more comfortable with thermal relations, we can apply them to the analysis of electric circuits. The dynamical models created for the phenomena observed and described above provide a point in case. We may, without loss of meaning and precision, transfer a model of the equilibration of water levels in two communicating tanks to the analogous model of equilibration of voltages of two communicating capacitors in a simple electric circuit. All we have to do is change the names of the variables appearing in the first model and adjust numerical values of parameters such as capacitance and resistance.

\section{Creating Visual Metaphors for Introducing Energy}

Up to this point, models of dynamical processes have been created based upon only two of the three basic aspects of the gestalt of a force: quantity (amount of fluid substance) and quality or intensity and its differences (tension). This description includes secondary metaphoric projections of image schemas such as container and force dynamic schemas such as letting or opposing that are instrumental in structuring our knowledge of constitutive relations.

There is an important third basic aspect: a force is perceived as a powerful agent: the agent can be more or less powerful. What does this mean for natural language use and metaphors, and how is this aspect reflected in models of physical processes? 

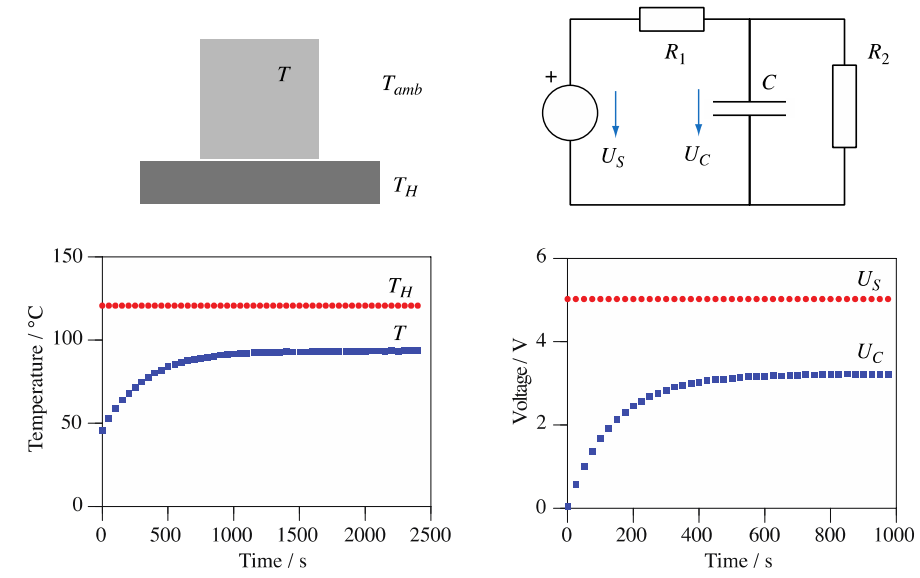

Fig. 5 Experiments and data for two phenomena can be modeled analogously to simultaneous filling and draining of a tank as in Fig. 3. Left: A metal block sits on a heater whose temperature $T_{H}$ is kept constant (ambient temperature: $\mathrm{T}_{\mathrm{amb}}$ ). Right: Electric circuit allowing for simultaneous charging and discharging of a capacitor

\section{The Gestalt of Direct Manipulation}

The perception of the power of an agent is related to our basic sense of causation. Studies in cognitive linguistics suggest that this, in turn, may be the result of the fundamental perceptual gestalt of direct manipulation (Lakoff and Johnson 1980) — this makes our sense of causation a result of embodied experience. We use this insight to suggest to our students that, in order to understand the power of agents, we need to study their interactions - how one agent lets a "patient" undergo a process.

The notion of energy renders the idea of power of a forces of nature formal and quantitative, i.e., useful for a formal science such as physics. Take, for example, a water pump driven electrically. A model of the systemic operation of a continuously running pump involves electric voltage (tension) and flow of electric charge on the one hand, and pressure difference and volume current of fluid on the other. Now, quantifying how much water can be pumped how high per unit time by a quantity of electricity flowing per unit time across a given voltage must involve a new concept-power, understood as the rates at which a driving process makes energy available and the driven process uses it (for a visual metaphoric rendering of this idea of coupling of processes, see the section on process diagrams below).

The description given is that of an ideal pump. In reality, the hydraulic power is smaller than the electric power. If we understand power as the measure of the rates of making energy available and using it, we are led to questions such as 'is there another process driven by the electric phenomenon,' and 'what happened to the "missing" energy?' And, after all, where does the energy the electric process makes available come from? 


\section{Extending the Energy Concept}

As we have discussed at the end of "Identifying the Imaginative Structure of Continuum Physics", we use Carnot's image of the power of a waterfall as a first step toward formalizing the notion of energy. This notion is extended to include the concepts of energy storage and transfer, allowing for a law of balance of energy to be formulated. It is assumed that energy can neither be produced nor destroyed: there is no production term for energy in the expression for its balance.

In order to deal with energy transfer imaginatively, we make use of the idea that the fluidlike quantities of the various processes, i.e., amount of fluid or substance, charge, entropy, or momentum, are energy carriers. ${ }^{8}$ [This idea has been introduced, explained, and applied in high school courses by Falk et al. (1983), Herrmann (2000), and Schmid (1982).] Energy carriers flow from a system to another, together with energy.

Energy carriers can also accumulate, and store energy with them in a specific region of space. Energy storage is dealt with from the viewpoint of a substance metaphor of energy. Despite its shortcomings, the substance metaphor is ubiquitous even in formal and technical language (Lancor 2014) (a system has energy, absorbs and emits energy, keeps or loses energy, etc.). ${ }^{9}$ In order to formulate the law of balance of energy, we appeal to the projections of the same image schemas that give us the general sense of balancing or accounting for a substance, namely, SUBSTANCE, AMOUNT, CONTAINER, SURFACE, IN-OUT, PATH (source-path-goal), COLLECTION, and FLOW (see "Identifying the Imaginative Structure of Continuum Physics").

\section{Process Diagrams as Visual Metaphors}

Dealing with energy properly is anything but trivial. For this reason, we have devised a generalized form of process diagram that uses visual metaphors to make the role of energy in physical and chemical processes as plain as possible (Fuchs 2010 [1996]; Corni et al. 2019a).

We start with Sadi Carnot's waterfall image of physical processes (Fig. 6). In a driving (i.e., spontaneous) process, a fluidlike quantity flows from a higher to a lower level (potential), thereby making energy available at a certain rate that is used (again at a certain rate) to drive one or more follow-up processes. A process that is driven is constituted by a fluidlike quantity being pumped uphill.

A device that couples a driving process to one or more driven processes (Fig. 6, center and right) is represented as a box with flows of fluidlike quantities going in and out (and maybe being produced) as well as flowing down and being pumped up. The rate at which energy is made available or used, i.e., power, is symbolized by fat arrows next to the "waterfall" or the rise of a fluidlike quantity.

\footnotetext{
8 This image works for conductive transports. Convection and radiation need to be dealt with separately (Fuchs 2010 [1996], Chapters 7 and 8).

9 At the 2017 GIREP conference in Dublin (2-7 of July), this question has been discussed in quite some detail during a roundtable event organized by Paula Heron (U Washington).
} 
(a)

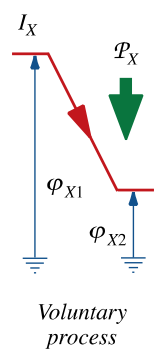

(b)

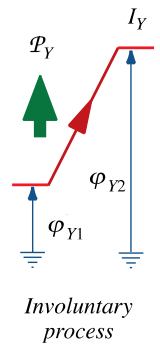

Pipes, turbine,

(c) and generator

Fig. 6 Waterfall image and process diagrams. a A process X makes energy available in the fall of a quantity through a potential difference. The energy can be used by a process Y. Power, i.e., the rate at which energy is made available or used is symbolized by fat arrows pointing down or up, respectively. b Process diagram of ideal electric water pump. c Non-ideal system representing a hydroelectric power plant. Symbols: I: current of fluidlike quantity; $\varphi$ : potential; P: power; Q: charge; V: volume; m: mass; p: pressure; circle with dot: production rate

Transport and storage of energy can be visualized in process diagrams as well (Fig. 7). A transport of energy (carried by an energy carrier) takes place between two devices in a chain of events. We use horizontal fat arrows to symbolize energy in transit. For storage, we use a little container symbol inside a box denoting a device (a storage element). Note that energy is stored along with other fluidlike quantities.

The approach to physical processes and energy described here has been represented even more imaginatively in a short animation created by an art student at the School of the Arts in Zurich (Deichmann 2014). In a story of an inventor trying to create a perpetuum mobile, fluidlike quantities are symbolized as little spirits that carry and hand over dust (energy) as the processes in the machine are running. The story is a well-crafted allegory of the Earth as an open flow system. A detailed description of the movie and a discussion of its relation to narrative structures of physics in given by Corni et al. (2019b) and Fuchs et al. (in press).

\section{Imaginative Primary Physical Science: Questions and Challenges}

Our approach to teacher education in the field of physical science raises a number of important issues that, so far, have not been addressed in depth and possibly cannot all be answered and solved from within physics or cognitive science (or the learning sciences) taken separately. As we have tried to point out, widening our view to include a number of disciplines and tie their integration to a central questionthat of the nature of experience, i.e., the joint action of perception and conception of Forces of Nature-should lead to a challenge interesting and wide enough to be worthy of attention and continued investigation (Fig. 1).

In lieu of a summary of the positions taken in this paper, we offer here a small list of questions and challenges raised by an imaginative approach to primary physics for student teachers. 


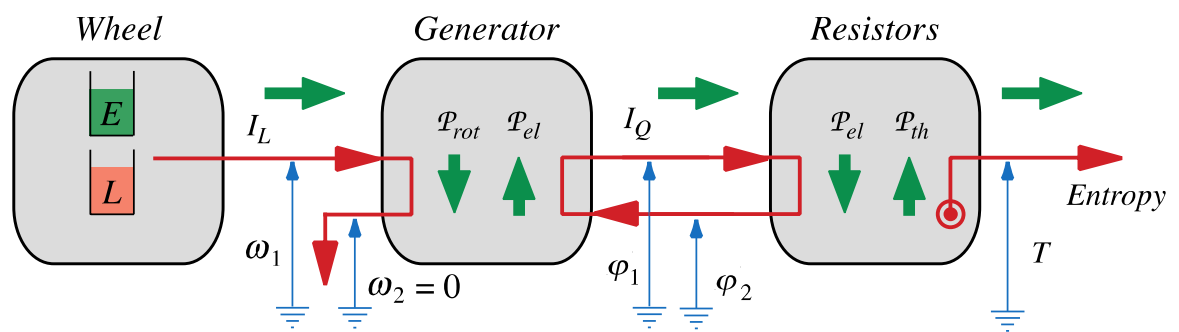

Fig. 7 Process diagram of a sequence of devices (here, a flywheel, electric generator, and resistors). The diagram visualizes transport and storage of energy in addition to power (making energy available and using it). Symbols: $\omega$ : angular speed; L: angular momentum; T: temperature; E: stored energy. Horizontal fat arrows denote energy transfers between devices or elements; container symbols (in the leftmost box) symbolize storage

\section{Continuity Between Everyday and Scientific Thinking}

To date, a good number of investigations into the use of various types of metaphor in physics and other sciences have been performed (Amin 2009; Amin et al. 2015; Lancor 2014; Brookes and Etkina 2009), and narrative (or story-telling) has been a much-debated theme in science education (Corni 2014; Kubli 2001; Klassen 2010). It has also been pointed out that natural historical science, in particular, is commonly rendered in narrative form (Norris et al. 2005). Still, such investigations have fallen short of saying outright that the theories of a science such as physics are the product of human imagination, ${ }^{10}$ and what that might mean for both the form of formal representations and learning about them.

If we accept, for the moment, the stronger claim made in this paper-namely, that reasoning in physics follows metaphoric and narrative structures-we can formulate a corollary: there is an important degree of continuity between everyday and scientific forms of thinking. We shall briefly take a critical look at this proposition and suggest that questions raised by it provide fertile ground for further investigations.

Assuming that this continuity exists, we still have to make clear how we arrive at formal science. We certainly do not want to claim that we just need a mythic mind and some time to grow up and, voila, there is science at our fingertips. We still have to design a course of action, mostly for secondary education, that adds elements of formal science. Egan's (1997) scheme of recapitulation of cognitive tools that come

\footnotetext{
${ }^{10}$ This statement needs to be qualified-we do not want to insinuate that what we have called imaginative approaches have not had their place in investigations of the role of science and science education. We restrict our remark to our claim that formal theories (particularly continuum physics) bear the mark of the imaginative structures found in our conceptualizations of Forces of Nature. Even more to the point, we restrict our remark to the claim that continuum physics can/could be rendered narratively. In the wider arena of studies of the role of human imagination in science, we should refer to Latour (1987) for a radical view of the role of social structures; or to Nersessian (2008) and Gentner (2002) for how analogy has been instrumental in the construction of some physical theories; or to studies showing how metaphors and analogy can lead us astray in science (Ball 2011; Harrer 2017). (We thank an anonymous reviewer for pointing out these important references).
} 
after an early stage of mythic understanding may shed some light upon the question of how to bridge the distance between basic figurative understanding of natural phenomena and formal scientific discourse-see Fuchs (2012) for a discussion of these points. Still, even if there is some merit to a claim of strong continuity between everyday and scientific forms of thinking, we will have to show exactly what this continuity is in concrete cases, how far it goes, and how it relates to the process of conceptual growth in an individual in the course of learning.

\section{Theories, Knowledge in Pieces, and a Narrative Practice Hypothesis}

There is another issue relating to the claim that the conceptual structure of physics is basically metaphoric and narrative, that can be of interest to researchers in science education and special related fields such as conceptual change research. In conceptual change circles, despite progress and convergence (Amin and Levrini 2018), there is considerable disagreement about the question of whether young learners possess theories about the natural world (albeit commonly mistaken ones; Chi et al. 1994), or if knowledge comes, as diSessa (1993) puts it, in pieces. Our approach circumvents this issue by suggesting that learning about the natural world can be usefully "jumpstarted" through hearing, reading, retelling, and working from, stories of forces of nature that serve as an additional form of experience ${ }^{11}$ of the natural world and contain elements of imaginative rationality important to human thought in general. Through the addition of later cognitive tools, this form of understanding would then slowly evolve into more elaborate and formal, i.e., scientific forms of understanding. ${ }^{12}$

This idea is similar to the Narrative Practice Hypothesis advanced by Hutto (2007), which deals with the question of how we learn to understand other people. Here is an interesting question that might be answered in the future: Is the power of folk-physics similar to that of folk-psychology, and how do the folk versions evolve into scientific versions if we assume that both make use of the same basic figurative structures of the human mind?

\section{Imaginative Approaches to Science and Integration with Humanities}

Student teachers look upon their education as a part of the humanities and are, by and large, little inclined toward the natural sciences. The same may be said about

\footnotetext{
11 With regard to literary stories, this point has been made forcefully, and in detail, by Marco Caracciolo in "The Experientiality of Narrative" (2014).

12 Here is an example of our didactics that suggests questions brought up by such an approach. We use a Winter Story (Fuchs 2010) about cold as a Forces of Nature when we introduce teacher students to narrative in physics. (The story is also used in various forms for children in primary school.) What is the effect of seeing a story of cold at work upon the minds of teacher students (and of small children)? To complicate the matter, what is the impact of understanding of physical science when an engineer speaks of "storing cold," or a meteorologist asks "where is the cold?". At what point, and how, do we guide learners to the point of appreciating that only one "character" of the heat-cold pair is needed to create a formal science of thermal dynamical phenomena?
} 
many of the members of the Department of Education of the University of Modena and Reggio Emilia, where this enterprise was stared, and the Faculty of Education of the Free University of Bozen-Bolzano, where development is continuing. As many of us involved in science know, even between the different fields of sciencebiology, chemistry, physics, or earth science - there is hardly any collaboration to be found.

However, we have seen how positively students react to the physics course described here and how some of them achieve a veritable integration of aspects of the humanities with aspects of natural sciences (Corni et al 2014a, b). ${ }^{13}$ And it seems, with physics having made a step in the direction of the humanities, there now is a "virus" that is spreading to a larger group of educators and researchers.

In 2010, we organized for the first time what has become a bi-annual conference Innovation in science education for primary school and kindergarten, at the crossroads between sciences and humanities at the University of Modena and Reggio Emilia ${ }^{14}$ This has turned into a venue for philosophers, linguists, cognitive scientists, biologists, and mathematicians where they contribute to what originally started in the physical sciences (Contini 2013; Corni et al. 2011, in press; Corni and Altiero 2014, 2015; Favilla 2015). Importantly, we were able to organize an International Exploratory Workshop on Narrative in Science funded by the Swiss National Science Foundation and held in Switzerland in the summer of 2015. ${ }^{15}$ As a response to the ideas worked out there, the Center for Metaphor and Narrative in Science was founded at the University of Modena and Reggio Emilia in 2016. ${ }^{16}$

Many contributions to metaphoric and narrative approaches to science education and to the work that is now concentrated at the Center for Metaphor and Narrative in Science, have come, and are continuing to come, from members of the University of Modena and Reggio Emilia and of the Free University of Bozen-Bolzano representing many of the fields that today make up cognitive science. This lets us hope that an integration of the sciences with humanities is a sustainable form of development in a department of teacher education.

Acknowledgements This work was supported by the Open Access Publishing Fund of the Free University of Bozen-Bolzano. We are indebted to an anonymous reviewer of a first version of this paper for extensive and in-depth feedback and for pointing out that the nature and status of our proposal should be discussed in some detail to make clear where it is novel and opens up avenues for new investigations that may lead to corrections, changes, and generalizations to the model. We would also like to thank Robin Fuchs who has invented characters used in stories of forces of nature for small children and who has coauthored some of these stories.

\footnotetext{
13 A detailed description of the course, outcomes, and reaction will be presented in a subsequent paper (Part II).

14 Materials including papers relating to the conference can be found at www.pse.unimore.it under Events.

15 See www.narrativescience.org/Events/EW_2015/EW_Main.html. Participants at the workshop have made some of their publications available that relate to applications of narratology to economics, physics, biology, education, and cognitive science.

16 See www.manis.unimore.it.
} 
Funding No funding employed form the research connected to this article.

\section{Compliance with Ethical Standards}

Ethical Approval This article does not contain any studies with animals performed by any of the authors. This article does not contain any studies with human participants performed by any of the authors.

Open Access This article is licensed under a Creative Commons Attribution 4.0 International License, which permits use, sharing, adaptation, distribution and reproduction in any medium or format, as long as you give appropriate credit to the original author(s) and the source, provide a link to the Creative Commons licence, and indicate if changes were made. The images or other third party material in this article are included in the article's Creative Commons licence, unless indicated otherwise in a credit line to the material. If material is not included in the article's Creative Commons licence and your intended use is not permitted by statutory regulation or exceeds the permitted use, you will need to obtain permission directly from the copyright holder. To view a copy of this licence, visit http://creativecommons.org/licen ses/by/4.0/.

\section{References}

Amin, T. G. (2009). Conceptual metaphor meets conceptual change. Human Development, 52(3), $165-197$.

Amin, T. G., Jeppsson, F., \& Haglund, J. (2015). Conceptual metaphor and embodied cognition in science learning: Introduction to special issue. International Journal of Science Education, 37(5-6), $745-758$.

Amin, T. G., \& Levrini, O. (2018). Converging perspectives on conceptual change. London: Routledge.

Ball, P. (2011). A metaphor too far. Nature. https://doi.org/10.1038/news.2011.115.

Bejan, A., Tsatsaronis, G., \& Moran, M. (1996). Thermal design and optimization. New York: Wiley.

Brookes, D. T., \& Etkina, E. (2009). 'Force', ontology, and language. Physical Review Special Topics: Physics Education Research, 5(1), 010110.

Bruner, J. S. (1990). Acts of meaning. Cambridge: Harvard University Press.

Callendar, H. L. (1911). The caloric theory of heat and Carnot's principle. Proceedings of the Physical Society of London, 23(1), 153-189.

Caracciolo, M. (2014). The experientiality of narrative: An enactivist approach. Berlin: de Gruyter.

Carnot, S. (1824). Réflexions sur la puissance motrice du feu et sur les machines propres a développer cette puissance. Paris: Bachelier.

Chi, M. T. H., Slotta, J. D., \& de Leeuw, N. (1994). From things to processes: A theory of conceptual change for learning science concepts. Learning and Instruction, 4, $27-43$.

Contini, A. (2013). Metafora e razionalità immaginativa. In F. Corni (Ed.), Le scienze nella prima educazione. Un approccio narrativo a un curricolo interdisciplinare (pp. 35-57). Trento: Erickson.

Corni, F. (Ed.). (2013). Le scienze nella prima educazione. Un approccio narrativo a un curricolo interdisciplinare. Trento: Erickson.

Corni, F. (2014). Stories in physics education (Vol. 145). Cham: Springer.

Corni, F., \& Altiero, T. (Eds.). (2014). Innovazione nella didattica delle scienze nella scuola primaria e dell'infanzia: Al crocevia fra discipline scientifiche e umanistiche (Vol. II). Mantova: Universitas Studiorum.

Corni, F., \& Altiero, T. (Eds.). (2015). Innovazione nella didattica delle scienze nella scuola primaria e dell'infanzia: Al crocevia fra discipline scientifiche e umanistiche (Vol. III). Mantova: Universitas Studiorum.

Corni, F., Altiero, T., Landini, A. (Eds.) (in press). Innovazione nella didattica delle scienze nella scuola primaria e dell'infanzia: Al crocevia fra discipline scientifiche e umanistiche (Vol. IV). Padova: CLEUP.

Corni, F., Fuchs, H. U., \& Dumont, E. (2019a). Conceptual metaphor in physics education: Roots of analogy, visual metaphors, and a primary physics course for student teachers. Journal of Physics: Conference Series, 1286, 012059. https://doi.org/10.1088/1742-6596/1286/1/012059. 
Corni, F., Fuchs, H. U., Giliberti, E., \& Mariani, C. (2014a). Primary school teachers: Becoming aware of the relevance of their own scientific knowledge. In M. Taşar (Ed.), Proceedings of the world conference on physics education 2012 (pp. 1063-1072). Istanbul: Pegem Akademi.

Corni, F., Fuchs, H. U., Landini, A., \& Giliberti, E. (2019b). Visual and gestural metaphors for introducing energy to student teachers of primary school and kindergarten levels. Journal of Physics: Conference Series, 1287, 012043. https://doi.org/10.1088/1742-6596/1287/1/012043.

Corni, F., Fuchs, H. U., \& Savino, G. (2018). An industrial educational laboratory at Ducati foundation: Narrative approaches to mechanics based upon continuum physics. International Journal of Science Education, 40(3), 243-267.

Corni, F., Giliberti, E., \& Fuchs, H. U. (2014b). Student teachers writing science stories: A case study. In C. P. Constantinou, N. Papadouris, \& A. Hadjigeorgiou (Eds.), ESERA 2013: Science education research for evidence-based teaching and coherence in learning (pp. 2494-2505). Istanbul: Pegem Akademi.

Corni, F., Mariani, C., \& Laurenti, E. (Eds.). (2011). Innovazione nella didattica delle scienze nella scuola primaria: Al crocevia fra discipline scientifiche e umanistiche (Vol. I). Modena: Edizioni Artestampa.

Deichmann, M. (2014). Im übertragenen Sinne. Metaphern und Bildvergleiche in der Wissernschaft (Bachelor thesis). Zürcher Hochschule der Künste, Zurich. http://vimeo.com/98311515.

diSessa, A. A. (1993). Towards an epistemology of physics. Cognition and Intelligence, 10(2-3), $105-225$.

Dumont, E., Fuchs, H. U., Maurer, W., Venturini, F. (2014). From forces of nature to the physics of dynamical systems. EARLI: 9th International Conference on Conceptual Change. Bologna, Italy, August 26-29, 2014.

Egan, K. (1986). Teaching as story telling. Chicago: The University of Chicago Press.

Egan, K. (1988). Primary understanding. Education in early childhood. New York: Routledge.

Egan, K. (1990). Romantic understanding. The development of rationality and imagination. New York: Routledge.

Egan, K. (1997). The educated mind. How cognitive tools shape our understanding. Chicago: The University of Chicago Press.

Egan, K. (2002). Getting it wrong from the beginning: Our progressivist inheritance from Herbert Spencer, John Dewey, and Jean Piaget. New Haven: Yale University Press.

Egan, K. (2013). Il contributo della fantasia alla costruzione del senso della realtà nei bambini. In F. Corni (Ed.), Le scienze nella prima educazione. Un approccio narrativo a un curricolo interdisciplinare. Erickson: Trento.

Falk, G. (1985). Entropy, a resurrection of Caloric: A look at the history of thermodynamics. European Journal of Physics, 6, 108-115.

Falk, G., Herrmann, F., \& Schmid, G. B. (1983). Energy forms or energy carriers? American Journal of Physics, 51(12), 1074-1077.

Fauconnier, G. (1997). Mappings in thought and language. Cambridge: Cambridge University Press.

Fauconnier, G., \& Turner, M. (2002). The way we think. Conceptual blending and the mind's hidden complexities. New York: Basic Books.

Favilla, E. (2015). Le storie nella didattica delle scienze: la Struttura linguistica e l'importanza del dialogo. In F. Corni \& T. Altiero (Eds.), Innovazione nella didattica delle scienze nella scuola primaria e dell'infanzia: Al crocevia fra discipline scientifiche e umanistich (pp. 109-130). Mantova: Universitas Studiorum.

Fuchs, H. U. (2002). Modeling of Uniform Dynamical Systems. Zurich: Orell Füssli. Retrieved from www.hansfuchs.org/MUDS.

Fuchs, H. U. (2006). From image schemas to dynamical models in fluids, electricity, heat, and motion. Examples, practical experience, and philosophy. Invited talk. In Proceedings of the 2006 GIREP conference. University of Amsterdam.

Fuchs, H. U. (2010 [1996]). The Dynamics of Heat. Second Edition. Graduate Texts in Physics. New York: Springer (First Edition: 1996)

Fuchs, H. U. (2010). Force dynamic gestalt, metafora e pensiero scientifico. In F. Corni, C. Mariani, \& E. Laurenti (Eds.), Innovazione nella didattica delle scienze nella scuola primaria: Al crocevia fra discipline scientifiche e umanistiche (pp. 8-18). Modena: Artestampa.

Fuchs, H. U. (2012). Dal pensiero mitico alla conoscenza della natura. In F. Corni \& T. Altiero (Eds.), Innovazione nella didattica delle scienze nella scuola primaria e dell'infanzia: Al crocevia fra discipline scientifiche e umanistiche (pp. 9-34). Mantova: Universitas Studiorum. 
Fuchs, H. U. (2013). Il significato in natura. In F. Corni (Ed.), Le scienze nella prima educazione. Un approccio narrativo a un curricolo interdisciplinare. Trento IT: Erickson. English version: Meaning in nature: From schematic to narrative structures of science. Retrieved from www.hansfuchs.org/ LITERATURE/Literature.html.

Fuchs, H. U. (2014). The narrative structure of continuum thermodynamics. In C. P. Constantinou, N. Papadouris \& A. Hadjigeorgiou (Eds.), E-book proceedings of the ESERA 2013 conference: Science education research for evidence-based teaching and coherence in learning. Part 1 (pp. 50-51). Nicosia: European Science Education Research Association.

Fuchs, H. U. (2015). From stories to scientific models and back: Narrative framing in modern macroscopic physics. International Journal of Science Education, 37(5-6), 934-957.

Fuchs, H. U., Contini, A., Dumont, E., Landini, A., \& Corni, F. (2018). How metaphor and narrative interact in stories of forces of nature. In M. Hanne \& A. Kaal (Eds.) Narrative and Metaphor in Education. Look both ways. London: Routledge.

Fuchs, H. U., Dumont, E., Corni, F. (in press). The power of forces of nature: How narratives introduce us to the notion of energy. In F. Corni, T. Altiero, A. Landini (Eds.) Innovazione nella didattica delle scienze nella scuola primaria e dell'Infanzia: Al crocevia fra discipline scientifiche e umanistiche. Padova: CLEUP.

Gentner, D. (1983). Structure-mapping: A theoretical framework for analogy. Cognitive Science, 7 , $155-170$.

Gentner, D. (2002). Analogy in scientific discovery: The case of Johannes Kepler. In L. Magnani \& N. J. Nersessian (Eds.), Model-based reasoning: Science, technology, values (pp. 21-39). New York: Kluwer Academic Publishers.

Grady, J. (1997). Foundations of meaning: Primary metaphors and primary scenes. Ph.D. Dissertation, University of California, Berkeley.

Grady, J. (2005a). Image schemas and perception: Refining a definition. In B. Hampe (Ed.), From perception to meaning. Image schemas in cognitive linguistics. Berlin: Mouton de Gruyter.

Grady, J. (2005b). Primary metaphors as input to conceptual integration. Journal of Pragmatics, 37, 1595-1614.

Hampe, B. (2005). From perception to meaning. Image schemas in cognitive linguistics. Berlin: Mouton de Gruyter.

Harrer, B. W. (2017). On the origin of energy: Metaphors and manifestations as resources for conceptualizing and measuring the invisible, imponderable. American Journal of Physics, 85(6), 454-460.

Herman, D. (2002). Story logic. Lincoln, NE: University of Nebraska Press.

Herman, D. (2009). Basic elements of narrative. Chichester: Wiley-Blackwell.

Herrmann, F. (1989-1999). Der Karlsruher Physik-Kurs. Sekundarstufe 1 (3 Bände), Sekundarstufe 2 (2 Bände), 2 Lehrerbände. Köln: Universität Karlsruhe and Aulis-Verlag.

Herrmann, F. (2000). The Karlsruhe physics course. European Journal of Physics, 21, 49-58.

Hestenes, D. (2006). Notes for a modeling theory of science, cognition and instruction. In Proceedings of the 2006 GIREP conference: Modelling in Physics and Physics Education, University of Amsterdam.

Hutto, D. (2007). The narrative practice hypothesis: Origins and applications of folk psychology. Royal Institute of Philosophy Supplement, 82(60), 43-68.

Johnson, M. (1987). The body in the mind. Chicago: University of Chicago Press.

Jou, D., Casas-Vazquez, J., \& Lebon, G. (1996). Extended irreversible thermodynamics (2nd ed.). Berlin: Springer.

Klassen, S. (2010). The relation of story structure to a model of conceptual change in science learning. Science \& Education, 19(3), 305-317.

Kockelman, P. (2016). Grading, gradients, degradation, grace. Part 1: Intensity and causality. HAU: Journal of Ethnographic Theory, 6(2), 389-423.

Kubli, F. (2001). Can the theory of narratives help science teachers be better storytellers? Science \& Education, 10(6), 595-599.

Lakoff, G. (1987). Women, fire, and dangerous things. Chicago: University of Chicago Press.

Lakoff, G., \& Johnson, M. (1980). Metaphors we live by. Chicago: University of Chicago Press.

Lakoff, G., \& Johnson, M. (1999). Philosophy in the flesh. New York: Basic Books.

Lakoff, G., \& Nunez, R. E. (2000). Where mathematics comes from. New York: Basic Books.

Lancor, R. (2014). Using metaphor theory to examine conceptions of energy in biology, chemistry, and physics. Science \& Education, 23(6), 1245-1267. 
Latour, B. (1987). Science in action: How to follow scientists and engineers through society. Cambridge: Harvard University Press.

Levi-Strauss, C. (1962). La Pensée sauvage. Paris, F: Librairie Plon. English translation (1966). The Savage Mind. Chicago, IL: University of Chicago Press.

Levi-Strauss, C. (1978). Myth and meaning. Toronto: University of Toronto Press.

Mares, J. J., Hubik, P., Sestak, J., Spicka, V., Kristofik, J., \& Stavek, J. (2008). Phenomenological approach to the caloric theory of heat. Thermochimica Acta, 474(1-2), 16-24.

Müller, I. (1985). Thermodynamics. Boston: Pitman.

Nersessian, N. J. (2008). Creating scientific concepts. Cambridge: MIT Press.

Norris, S. P., Guilbert, S. M., Smith, M. L., Hakimelahi, S., \& Phillips, L. M. (2005). A theoretical framework for narrative explanation in science. Science Education, 89(4), 535-563.

Ricoeur, P. (1984). Time and narrative (Vol. 3). Chicago: The University of Chicago Press.

Rosch, E. (1973). Natural categories. Cognitive Psychology, 4, 328-350.

Scheidegger, S., Fuchs, H. U., Zaugg, K., Bodis, S., \& Füchslin, R. M. (2013). Using state variables to model the response of tumour cells to radiation and heat: A novel multi-hit-repair approach. Computational and Mathematical Methods in Medicine, 2013, 587543.

Schmid, G. B. (1982). Energy and its carriers. Physics Education, 17, 212-218.

Schmid, G. B. (1984). An up-to-date approach to physics. American Journal of Physics, 52(9), 794-799.

Sieniutycz, S., \& De Vos, A. (Eds.). (2000). Thermodynamics of energy conversion and transport. New York: Springer.

Talmy, L. (2000). Toward a cognitive semantics. Volume I: Concept structuring systems. Volume II: Typology and process in concept structuring. Cambridge: The MIT Press.

Thoma, J. U. (1975). Entropy and mass flow for energy conversion. Journal of the Franklin Institute, 299(2), 89-96.

Thoma, J. U., \& Mocellin, G. (2006). Simulation with entropy thermodynamics understanding matter and systems with bondgraphs. Berlin: Springer.

Truesdell, C. A. (1984). Rational thermodynamics. New York: Springer.

Truesdell, C. A., \& Noll, W. (1965). The non-linear field theories of mechanics. In S. Flügge (Ed.), Encyclopedia of physics (Vol. III/3). Berlin: Springer.

Truesdell, C. A., \& Toupin, R. A. (1960). The classical field theories. In S. Flügge (Ed.), Encyclopedia of physics (Vol. III/1). Berlin: Springer.

Turner, M. (1996). The literary mind. The origins of thought and language. New York: Oxford University Press.

Wise, M. N. (2011). Science as (historical) narrative. Erkenntnis, 75(3), 349-376.

Publisher's Note Springer Nature remains neutral with regard to jurisdictional claims in published maps and institutional affiliations. 